\title{
Lifestyle Implications of Home Mechanical Insufflation-Exsufflation for Children With Neuromuscular Disease and Their Families
}

\author{
Fiona C Moran DClinPhysio, Alicia J Spittle PhD, and Clare Delany PhD
}

\begin{abstract}
BACKGROUND: Mechanical insufflation-exsufflation (MI-E) is increasingly used in the home management of children with neuromuscular disease. Research to date has focused on the effect of MI-E on physical health. The aim of this study was to qualitatively investigate the impact of home MI-E on the child and family's lifestyle. METHODS: Eight parents and 3 children participated in semistructured interviews. RESULTS: Five themes emerged from parent interviews demonstrating: (1) lifestyle implications, (2) parents becoming experts, (3) parents developing a sense of control over their child's condition, (4) an element of extra care, and (5) impacts on the parent-child relationship. Developing themes from the child interviews showed them adjusting to and then relying on the device. Home MI-E medicalized the home, but the overall lifestyle impact was positive. CONCLUSIONS: Although involving a small number of subjects, this study demonstrated a mixture of opposing impacts of home MI-E on lifestyle, both enabling and disabling, which need to be considered when introducing home MI-E. The positive impacts included greater ability to manage the child's health, including avoidance of hospital admissions. Negative impacts were greatest for those parents who were sole operators of the device, including a frequently disrupted lifestyle. Key words: mechanical insufflation-exsufflation; lifestyle; neuromuscular disease; pediatric; Duchenne muscular dystrophy; spinal muscular atrophy. [Respir Care 2015;60(7):967-974. (C) 2015 Daedalus Enterprises]
\end{abstract}

\section{Introduction}

Spinal muscular atrophy types 1 and 2 and Duchenne muscular dystrophy are progressive, life-limiting neuromuscular diseases that present in early childhood. Although highly variable in their presentation, these conditions have a debilitating and dramatic impact on a child's health and lifestyle over time and result in premature death during

Dr Moran is affiliated with the Department of Physiotherapy, and Dr Delany is affiliated with the Children's Bioethics Centre, The Royal Children's Hospital, Parkville, Victoria, Australia. Drs Spittle and Delany are affiliated with the Department of Physiotherapy, Melbourne School of Health Sciences, University of Melbourne, Victoria, Australia. Dr Spittle is also affiliated with the Murdoch Childrens Research Institute, Parkville, Victoria, Australia.

The authors have disclosed no conflicts of interest.

Correspondence: Fiona C Moran DClinPhysio, Department of Physiotherapy, The Royal Children's Hospital, Flemington Road, Parkville, Victoria 3052, Australia. E-mail: fiona.moran@rch.org.au.

DOI: $10.4187 /$ respcare.03641 childhood or early adult years, usually due to respiratory failure. ${ }^{1}$ As health deteriorates, increasing medical interventions and technologies (eg, noninvasive ventilation, mechanical insufflation-exsufflation (MI-E) and enteral feeding) are introduced into the child's ongoing care at home. MI-E is used when respiratory muscle weakness results in an ineffective cough and impaired secretion clearance. It involves the application of cycling positive and negative pressure to the airway, facilitating an effective cough and adequate secretion clearance. Studies examining its home-based clinical effectiveness demonstrate that it is safe and well tolerated ${ }^{2-4}$; creates an increased peak cough flow ${ }^{2,5-8}$; results in reduced hospital stay ${ }^{9}$; and when used as part of a wider home management protocol involving other therapies, such as noninvasive ventilation, achieves reduced rates of pneumonia and hospital stay. $5,6,10,11$

However, there have been comparatively few studies examining the broader impact of home-based MI-E on children and their families. In a previous pilot study, ${ }^{9}$ parents reported positive impacts of MI-E, including being able to manage respiratory exacerbations without hospital 
admission, but also negative lifestyle impacts, such as feeling increasingly housebound. The International Classification of Functioning, Disability and Health model ${ }^{12}$ and concepts of family-centered care are 2 health-care models that remind clinicians to consider the wide-ranging impacts of a condition on not only body functions and structure but also on activities, participation, a child's environment, and personal family circumstances. In the pediatric health setting, MI-E as an example of a new technology in home care raises the need to consider the impact not only on a child's physical health but also on broader aspects of lifestyle and the family's well-being. ${ }^{13,14}$

\section{See the Related Editorial on Page 1081}

In this study, we sought to broaden the research on MI-E from a clinical focus to include an examination of the lived experience of children with spinal muscular atrophy and Duchenne muscular dystrophy and their families who have transitioned to using MI-E in the home.

\section{Methods}

Qualitative research methodology and phenomenology were used to examine the nature of MI-E use, enabling an in-depth exploration of subjects' experiences, including documenting their responses and perspectives in their own words. Phenomenology provides a theoretical frame to focus on how individuals exposed to a certain phenomenon (home MI-E), understand and describe their specific experience. ${ }^{15,16}$ Rather than objectively measuring and controlling their experiences, phenomenology examines what is perceived by the individuals, acknowledging that there may be a variety of perspectives and interpretations. It takes into account the relationship between an individual's consciousness and the phenomenon, ${ }^{17}$ recognizing how the different experiences of each individual contributes to a reality that is based on multiple perspectives. ${ }^{18} \mathrm{~A}$ phenomenological approach evaluates the body as lived by the patient, where illness is experienced from within and affects all aspects of life. This perspective is vital for healthcare practitioners so that they may seek to understand the wider impact of illness (and treatment) on patients' and families' lives. ${ }^{17}$ In this study, the phenomenological approach allowed us to investigate the impact of home MI-E not as a separate therapeutic entity but rather within the setting of the subjects' illness and lives. Information gained from each individual was analyzed and compared across subjects, allowing the development of themes that described the essence of the overall experience. ${ }^{15}$

The interviews were semistructured with questions based around 6 broad areas of questioning: (1) usage, (2) initial thoughts and reactions, (3) current thoughts, (4) impact

\section{QUICK LOOK}

\section{Current knowledge}

Noninvasive ventilation and mechanical insufflationexsufflation (MI-E) are common treatments in the care of pediatric neuromuscular disease to improve cough and facilitate secretion clearance. These treatments appear to be safe and well tolerated. Combined with a comprehensive home management program, these therapies assist in reducing hospital admissions and pneumonia rates.

\section{What this paper contributes to our knowledge}

In a small number of subjects, this study demonstrated opposing impacts of home MI-E on lifestyle, both enabling and disabling, which need to be considered before implementation. The positive impacts included greater ability to manage the child's health, including avoidance of hospital admissions. Negative impacts were greatest for those parents who were sole operators of the device and included a frequently disrupted lifestyle.

on lifestyle, (5) impact of technology within the home, and (6) advice for the future. Questions were mostly openended, so the interviewer and interviewee could deviate from the line of questioning to explore a specific area in more detail, allowing conversation to develop in the areas most important to them. ${ }^{19,20}$

Subjects were drawn from a single tertiary pediatric hospital in Australia and formed 2 groups: parents and children. Inclusion criteria for the parents were: (1) child had a confirmed diagnosis of Duchenne muscular dystrophy or spinal muscular atrophy, and (2) child had commenced home MI-E on an ongoing basis within the previous $10 \mathrm{y}$. Exclusion criteria were: (1) child was $18 \mathrm{y}$ or older at the time of MI-E commencement, or (2) child had been using MI-E at home on an ongoing basis for $<6$ months. Inclusion and exclusion criteria were the same for the children with the addition of one inclusion criterion: that the child was $10 \mathrm{y}$ or older at the time of the study.

Ethics committee approval was obtained from The Royal Children's Hospital in Melbourne, Australia. All eligible subjects were contacted by the primary investigator. The primary investigator was a physiotherapist known to the potential subjects. To reduce any potential bias or reluctance to speak freely during interviews, the difference between the investigator's role as a clinician and as a researcher was explained to subjects. Informed consent was obtained from all parents and from both a parent and the child for children. The sample size was not predetermined 


\section{Home MI-E for Children With Neuromuscular Disease}

Table 1. Subject Characteristics

\begin{tabular}{|c|c|c|c|c|c|c|}
\hline Child's Diagnosis & Age (y) & Sex & $\begin{array}{l}\text { Time Using } \\
\text { Home MI-E (y) }\end{array}$ & $\begin{array}{l}\text { Home NIV } \\
\text { Use }\end{array}$ & Parent Subjects & Child Subjects \\
\hline Spinal muscular atrophy type 2 & 16 & Female & 4 & Yes & Mother & Yes \\
\hline Spinal muscular atrophy type 2 & 8 & Male & 4 & Yes & Mother & Too young \\
\hline Spinal muscular atrophy type 2 & 10 & Male & 3 & Yes & Father & Yes \\
\hline Duchenne muscular dystrophy & 18 & Male & 3 & Yes & Mother & Yes \\
\hline Spinal muscular atrophy type 2 & 12 & Male & 2 & No & Father & Declined \\
\hline Spinal muscular atrophy type 2 & 4 & Male & 2 & No & Mother & Too young \\
\hline Spinal muscular atrophy type 2 & 4 & Female & 2 & No & Mother + Father & Too young \\
\hline $\begin{array}{l}\text { MI-E = mechanical insufflation-exsufflatior } \\
\text { NIV = noninvasive ventilation }\end{array}$ & & & & & & \\
\hline
\end{tabular}

to achieve a certain degree of statistical power. Instead, it was purposeful and flexible with the aim of seeking subjects who had used home MI-E and could therefore provide their views and perspectives about its impact on their lives. All eligible subjects were approached to maximize subject numbers with the aim being to achieve data saturation. Data saturation was determined to have been reached when there were few new data being obtained from subsequent interviews. ${ }^{16}$

Following recruitment and consent, a mutually convenient time and location were arranged for the interview. Interviews were performed at the hospital, at the subject's home, or via telephone. Parent interviews took $\sim 20 \mathrm{~min}$, and child interviews took $\sim 10 \mathrm{~min}$. Interviews were audiorecorded and transcribed.

Interview transcripts (using pseudonyms for subjects and family members) were reviewed separately by 2 investigators and thematically analyzed in a process similar to that outlined by Burnard et al. ${ }^{21}$ First, key statements within each transcript were highlighted and labeled with a descriptive category. The highlighted sections from all transcripts were then collated, and similar categories were grouped together. These groups were labeled with an overall theme. Example quotes are included in the results section to demonstrate themes; these quotes are included verbatim apart from removal of filler words (eg, um and like) and repetitive words. Parent and child transcripts were analyzed separately. Data saturation was used to determine the sample size for parents. Five themes emerged, and interviews were stopped after no new themes arose. ${ }^{16}$ The children's sample size was determined by the number of children available during the time period of the study.

\section{Results}

Interviews were performed with 8 parents ( 5 mothers) of a total of 14 eligible parents, representing 7 of 8 eligible families. Three children ( 2 male) of a total of 4 eligible children were also interviewed. All subjects used the
CoughAssist CA-3200 device (Philips Respironics, Murrysville, Pennsylvania) via a face mask. Of the 7 family units who participated in interviews, 5 used MI-E at least once or twice daily when well, with increased usage when unwell. The other 2 families used MI-E only when the child was unwell. Further subject details are provided in Table 1 .

When MI-E was first introduced to the child's home care, parents were instructed in its use by a physiotherapist in at least 2 structured education sessions, including practical experience using MI-E with their child. For those families who also had caregiver support, these caregivers were also trained in using MI-E in the same way as the parents if parental consent was given.

\section{Parent Interviews}

The parent interviews and thematic analysis resulted in the identification of 5 themes: (1) control, (2) becoming an expert, (3) extra care, (4) parent-child relationship, and (5) lifestyle. The quotes below provide representative examples of these themes.

Parent Interview Theme 1: Control. The introduction of home MI-E both increased control and highlighted areas in which there was a lack of control. For some parents, there was a lack of control or choice regarding the decision to begin home MI-E due to a lack of choice given by health professionals, a sense that the machine was needed for safety reasons, or a sense of obligation to do all they could for their child. Having MI-E in the home was also seen by some parents as a sign of disease progression, highlighting their overall lack of control over their child's disease.

In contrast to this, parents talked mostly of the increased sense of control that home MI-E gave them by enabling them to improve their child's health, better handle periods of illness, or avoid hospital presentations or admissions by being able to provide required treatments at home. Parents 


\section{Home MI-E for Children With Neuromuscular Disease}

felt able to do something for their child; they could improve the efficiency of their child's treatment and were not reliant on others.

\begin{abstract}
You can use it straight away, you don't have to wait for assistance like an ambulance or... take him straight to the hospital... it does save mucking around at the hospital. Because by the time you see a doctor, sometimes it's a long time. And in that time you could have helped him. (Mother)
\end{abstract}

In some cases, parents needed to control the use of the device and not let others use it.

\begin{abstract}
Because a couple of times when we were starting to use it, it was turned up a bit too high, or things were done a bit different, the breaths and stuff like that. I know how to use that now, but someone else might not see the signs of when she's asking to take it off or stop or whatever. (Mother)
\end{abstract}

Parent Interview Theme 2: Becoming an Expert. The process of using MI-E took parents on a journey, moving from novice to expert. Parents reported initially being positive about the concept of home MI-E; however, despite this positive approach, they were initially daunted, confused, or concerned when they started using the device. Over time and with increasing knowledge, parents became used to and comfortable using MI-E. With further use, parents moved from seeing themselves as just competent to seeing themselves as experts.

And back in those days, 4 years ago, I was a complete novice. Now I'm a professional specialist ... I consider myself a specialist. (Mother)

This development of ultimate expertise and comfort in using MI-E led parents to encourage others in similar situations to persist with using it through the difficult early stages. Most of the parents interviewed had a similar length of time using home MI-E (3-4 y). Those parents with a shorter period of home MI-E use $(<3 \mathrm{y})$ tended to talk less of their expertise in using MI-E and more of the learning process.

Parent Interview Theme 3: Extra Care. Home MI-E introduced an extra component to a child's care. For many parents, the extra care of using MI-E made respiratory treatment easier and quicker and was not seen as significantly difficult or burdensome compared with other aspects of their child's overall care.

Oh, well that's [using MI-E] insignificant. As in it's more of a pain to get him dressed or get him in the wheelchair, you just, well do anything like that so . . . the CoughAssist [MI-E] is just an easy part of the day. (Father)

However, for some families, the addition of home MI-E was a significant addition to their child's care requirements, particularly when parents were sole operators of the device without support of other caregivers.

\begin{abstract}
Because there have been times where the machine was at home and he needed to cough at school, and they've rung me up and I've had to race home to try and give it to him. (Father)
\end{abstract}

Parent Interview Theme 4: Parent-Child Relationship. Home MI-E was generally not seen by parents as changing their relationship with their child. Compared with the other care tasks they performed for their child, MI-E was usually one of the less difficult or intrusive tasks. Some parents merged their role of parent and caregiver with no delineation, whereas others fought to maintain a distinction between these roles.

I've combined into one person. I'm now the Mum slash nurse ... slash everything else person. There's just a very fine line between it all, it's just mished into one big ... mass me. (Mother)

We've just got to keep it different, so that we make it more fun ... it's like, we're not dressed up with stethoscopes and syringes ... It's you know, more fun, we're her parents. (Mother)

Parent Interview Theme 5: Lifestyle. This final theme drew together the previous 4 themes. One negative lifestyle impact reported was the disruption of parental lifestyle when they were sole operators of the device, resulting in them often being called back urgently to use the device.

It's sort of difficult in a way because me and Rick are the only ones who know how to operate it, so if there's a carer there, I have to do it before I go, or if she needs to use it or something, they have to ring me for me to come back from wherever I am. (Mother)

On the other hand, having MI-E at their disposal facilitated travel and outings.

Tristan went away. The school camp was for a week, he wasn't going to go, but I took the day off work to take him down to the camp ... that [MI-E device] was the one piece of equipment that came with us . . Just the thought that if we went to the hospital, if they might not have one, obviously ambulances when they turn up don't have them. But 


\section{Home MI-E for Children With Neuromuscular Disease}

the mere fact that I've got it, I'm happy to take him wherever. (Father)

It also allowed hospitalizations to be avoided, resulting in reduced family disruption. Home MI-E was easily incorporated into the family lifestyle in the same way that other changes as a result of the child's disease had also been incorporated.

\begin{abstract}
No, we've just become so used to having things in our lives, be they BiPAP [noninvasive ventilation] or suction machines ... or CoughAssists [MI-E]. I just don't even really notice that we use it, it's almost like his wheelchair. He's obviously in an electric wheelchair 24 hours a day. Well, when he's up and about, I don't even notice it anymore. (Mother)
\end{abstract}

Parents also felt that home MI-E allowed their child's life to be prolonged and their quality of life to be improved.

I think it does [have an impact on her quality of life] ... absolutely ... if you haven't got the ability to cough as a mainstream person ... anything to help you is better than nothing at all. (Mother)

\section{Child Interviews}

Although data saturation was not reached, thematic analysis of the child interviews resulted in the emergence of 4 related themes: (1) lifestyle, (2) adjusting to therapy, (3) medicalization of the home, and (4) reliance on the device.

Child Interview Theme 1: Lifestyle. With reference to the overall theme of lifestyle, the children expressed positive effects of home MI-E in that it improved their health and made them feel better. It also helped them avoid other treatments that they did not want.

Well, doesn't it mean that if I [didn't have home MI-E], you have to have tracheostomies and stuff. (18-y-old boy)

When asked about the impact that home MI-E had on their family's lifestyle, the children recognized that it made it easier for their parents to care for them and that it had positive effects.

Mainly all my brothers and that's because it means I don't have to come to hospital so they don't have to miss out on stuff because I have to come into the hospital. (16-y-old girl)
The only negative aspect of home MI-E mentioned by the children was the bulky nature of the device and the noise. The following themes demonstrate a progression from adjusting to therapy (theme 2) to accepting it as part of their medical treatment in their home (theme 3) and finally to relying on it (theme 4).

Child Interview Theme 2: Adjusting to Therapy. Children described how they were initially fearful of MI-E, not knowing what it would feel like.

I didn't know what it was going to feel like ... if it's going to feel any different or what it feels like. (10-y-old boy)

Once they started using MI-E, the children initially did not like it, but after using the device a few times, they got used to it and did not mind using it. An additional stage of adjusting to therapy for these children was learning when they needed to use it, and for those who used multiple medical devices (eg, noninvasive ventilation and MI-E), they had to learn the different indications for each.

Child Interview Theme 3: Medicalization of the Home. The children already had other medical devices in their homes when home MI-E was introduced, so the impact was not necessarily novel. The device was usually kept in the child's bedroom. Although the children stated that they did not mind this, one girl expressed a desire to personalize the machine to suit her room.

\begin{abstract}
It's not really a bad thing, it's just that color, it only comes in one color... I'd like purple. One of my friends that has it, she wants a pink one, and it only comes in like a bluey gray color ... Because if you have to use it and it has to be in your room, you want one that will suit everything else in your room ... yeah, if it's yours, you could personalize it and put what you want on it. (16-y-old girl)
\end{abstract}

Child Interview Theme 4: Reliance on the Device. There was a degree of reliance on MI-E for these children. When they needed to use the machine, the need was often urgent. They were also reliant on someone to operate the machine. This posed difficulties if there was no one around that was trained to use the device.

\section{Discussion}

This study represents the first qualitative investigation of the impact of home MI-E on children with neuromuscular disease. Parents and children reported both positive and negative impacts. Positive effects included better clinical health management of the children's respiratory care 


\section{Home MI-E for Children With Neuromuscular Disease}

and broader lifestyle effects, such as reduced hospitalization, leading to less lifestyle disruption and increased ability to participate in activities. These findings are consistent with our previous pilot study, ${ }^{9}$ in which some parents reported positive impacts, such as being able to manage respiratory exacerbations without hospital admission, but some parents reported negative lifestyle impacts, such as feeling increasingly housebound.

Both the children and their parents went through a process of adjustment to using MI-E at home. For parents, the transition involved moving from novice to expert, with expertise being acknowledged after at least $3 \mathrm{y}$ of use. Transitions from parent to expert caregiver have been similarly discussed in studies of home mechanical ventilation of children, in which parents reported a gradual process of learning, resulting ultimately in having greater knowledge than support staff. ${ }^{22,23}$ Recognition of this expertise has been shown to be important in the health professional-parent relationship. ${ }^{24,25}$

The children in this study reported relatively quick adjustment to using MI-E. This is not uncommon in children with chronic medical conditions, who approach living with medical technology differently from adults ${ }^{26}$ and already have relatively high levels of knowledge and comfort with medical technologies due to previous periods of illness and hospitalizations. ${ }^{27}$

Home MI-E represents an example of moving technology and care into the home setting. Other studies have described examples of home-care technology as a paradox between enabling and disabling. ${ }^{26,28}$ In this study, the majority of parents reported minimal negative impacts on the home. One explanation for the mostly positive reports is the already significant care needs of these children, so parents may not separate the impact of a particular treatment or technology from the overall impact of their child's progressive condition. ${ }^{29} \mathrm{~A}$ further explanation for the parents' positive evaluation of MI-E in this study relates to the parents' experience of greater control over their child's health. ${ }^{30}$ This small increase in control was reported as very important to participating parents, as they felt they could do something for their child. The concept of empowerment in caregivers has been recognized as particularly important when a child has a progressive condition over which there is very little control. ${ }^{30,31}$

Negative impacts included a lack of choice in shifting to home MI-E treatment. In other studies, parents similarly expressed concern about the lack of choice in considering life-support technologies (eg, ventilatory support) due to the consequences of not beginning ventilation ${ }^{32}$ and the potential quality-of-life benefits for the child. ${ }^{22} \mathrm{~A}$ second negative impact was a sense of loss or grief with the introduction of a new piece of equipment, marking a decline in their child's illness journey. Mah et al ${ }^{22}$ similarly discussed the effect of losing hope and a renewed sense of loss, with each new treatment strategy or piece of equipment representing a sign of further deterioration.

Although giving more control to parents, home MI-E introduced extra duties in the care of their child, and these were more pronounced when parents were or actively chose to be the sole operators of the device without the support of other caregivers. One explanation for opting to be the sole operator of the machine is the belief that it represents competent caregiving. ${ }^{33}$ To introduce others to the machine may result in mistakes, so another motivation may be to protect the child. For health professionals, this may mean that teaching others to operate the device before parents achieve expert status may result in less resistance from the parents. Having sufficient caregivers trained in using the device is important, as the child is reliant on them to operate the device, placing them in stressful situations if that person is not available.

Several recommendations for health professionals who are involved in introducing and supporting families when transitioning to home-based treatment technology have resulted from this study (Table 2). They relate to core concepts of family-centered practice ${ }^{14}$ as it applies to homebased MI-E. The recommendations highlight an important role for health professionals in preparing parents for the possible impact of MI-E and provide strategies to enhance the therapeutic alliance and relationship between hospitalbased staff and parents.

There were several limitations to this study. The first was the relatively small number of subjects, particularly child subjects. Although unintentional, the parents interviewed identified themselves as the primary operator of MI-E with their child. The exception was one family in which MI-E operation was evenly shared between parents, both of whom were interviewed. This meant that the impact of home MI-E on those not as involved in its use was not investigated and they may have had a different experience. The majority of parent subjects were mothers, a not uncommon finding in studies of caring for children with chronic health needs. ${ }^{34}$ Several mothers actively discouraged the researcher from recruiting their partner, stating "he won't be able to add anything else." These mothers all reported being the primary operator of MI-E; therefore, they may have felt that their partners did not have sufficient expertise in using MI-E to participate in the interview. Finally, the responses of the subjects may also have been influenced by the interviewer being a physiotherapist previously involved in the child's care. Efforts were made to limit this impact by explaining the role of the interviewer as a researcher, not a clinician at that time, but the subjects may still have been reluctant to make negative comments. ${ }^{19}$

The main strength of this study lies in the fact that it is the first investigation of the qualitative impact of home MI-E on children with neuromuscular disease. The use of qualitative 


\section{Home MI-E for Children With Neuromuscular Disease}

Table 2. Family-Centered Care Based Recommendations for Future Practice

\begin{tabular}{|c|c|}
\hline Core Concept & Recommendations and Clinical Applications \\
\hline Respect and dignity & $\begin{array}{l}\text { Respect and dignity for the parents' role } \\
\text { Recognize and acknowledge the inevitable } \\
\text { increase in expertise of parents in caring for } \\
\text { their child and adjusting to MI-E at home } \\
\text { - Involve them in clinical decision making } \\
\text { - Ensure they have a role in training other } \\
\text { caregivers for their child } \\
\text { - Seek their advice on MI-E use and } \\
\text { integration into daily life }\end{array}$ \\
\hline Information sharing & $\begin{array}{l}\text { Ensure information is shared to foster } \\
\text { collaboration between clinicians and parents } \\
\text { Ensure parents are involved early in the } \\
\text { decision making about MI-E use in the } \\
\text { home } \\
\text { - Discuss all potential benefits and burdens of } \\
\text { MI-E, including impacts on lifestyle as well } \\
\text { as clinical impacts } \\
\text { - Develop resources for parents (based on } \\
\text { evidence of previous parents' experiences, } \\
\text { videos of use, and tips) so parents can } \\
\text { engage with the processes of developing } \\
\text { expertise at a level that suits their needs } \\
\text { - Plan a staged approach to MI-E education } \\
\text { with different timelines for children and } \\
\text { parents to enable children's concerns to be } \\
\text { addressed initially, followed by parents' } \\
\text { learning needs } \\
\text { - Repeat education for children at age- } \\
\text { appropriate levels throughout the course of } \\
\text { home MI-E, particularly as additional } \\
\text { technologies/treatments are introduced } \\
\text { - Plan for ongoing tailored evaluation and } \\
\text { discussion of the impacts of home MI-E for } \\
\text { each child and family }\end{array}$ \\
\hline Participation & $\begin{array}{l}\text { Encourage participation } \\
\text { - Negotiate with families about the timing of } \\
\text { the introduction of MI-E with consideration } \\
\text { of the potential benefits and burdens for } \\
\text { their situation }\end{array}$ \\
\hline Collaboration & $\begin{array}{l}\text { Assist families to transition hospital-based } \\
\text { therapies to the home } \\
\text { - Involve families in the education of } \\
\text { caregivers } \\
\text { - Work with individual families to ensure } \\
\text { sufficient support structures are in place, } \\
\text { including additional caregivers to use the } \\
\text { device to relieve pressure on families } \\
\text { - Suggest strategies to minimize the physical } \\
\text { (medicalizing) impact of the MI-E device on } \\
\text { the home environment, such as positioning } \\
\text { in the home and camouflage of the device }\end{array}$ \\
\hline
\end{tabular}

MI-E $=$ mechanical insufflation-exsufflation

methods was also a strength, as it allowed parents and children to describe the experience in their own words.
Future research in this area would benefit from a prospective design to reduce the impact of recall bias and enable the addition of quantitative quality-of-life measures before and following MI-E introduction. Future studies with larger subject numbers, particularly child subjects, would allow a greater depth of understanding of the issues faced. Larger subject numbers would also allow separate analysis and comparison of experiences between subjects based on background (eg, cultural or ethnic), age of child, or disease (with related impact on age of clinical deterioration). Multiple interviews, rather than a single interview with each subject, may allow greater exploration with time for reflection between interviews. This may be particularly beneficial for interviews with children so that they can take time to get used to the research process and develop rapport with the researcher. In future research, it would be important to obtain the opinions of siblings and non-primary caregivers. There may also be benefits gained through future research involving an observational aspect, so researchers can observe the use of MI-E in everyday family life. This may allow researchers to note some of the impacts that families have accepted as part of their lives and may not think of bringing up in an interview, as well as involvement of non-primary caregivers, who would be less likely to participate in an interview.

\section{Conclusions}

In summary, the transition to home MI-E was perceived positively by parents and children. Parents appreciated achieving expert status in MI-E use, and both parents and children appreciated the health benefits that improved lifestyle. This study has proposed a number of practical strategies, including early introduction of nonrelated caregivers operating the device, discussing potential impacts of the device on both health and lifestyle with parents and children, and reviewing ways to reduce the physical impact of the device on the home environment to maximize support and empowerment of families when transitioning to home use of MI-E.

\section{REFERENCES}

1. Gozal D. Pulmonary manifestations of neuromuscular disease with special reference to Duchenne muscular dystrophy and spinal muscular atrophy. Pediatr Pulmonol 2000;29(2):141-150.

2. Chatwin M, Ross E, Hart N, Nickol AH, Polkey MI, Simonds AK. Cough augmentation with mechanical insufflation/exsufflation in patients with neuromuscular weakness. Eur Respir J 2003;21(3): 502-508.

3. Garstang SV, Kirshblum SC, Wood KE. Patient preference for inexsufflation for secretion management with spinal cord injury. J Spinal Cord Med 2000;23(2):80-85.

4. Sancho J, Servera E, Vergara P, Marín J. Mechanical insufflationexsufflation vs. tracheal suctioning via tracheostomy tubes for pa- 


\section{Home MI-E for Children With Neuromuscular Disease}

tients with amyotrophic lateral sclerosis: a pilot study. Am J Phys Med Rehabil 2003;82(10):750-753.

5. Bach JR. Mechanical insufflation-exsufflation. Comparison of peak expiratory flows with manually assisted and unassisted coughing techniques. Chest 1993;104(5):1553-1562.

6. Bach JR, Smith WH, Michaels J, Saporito L, Alba AS, Dayal R, Pan J. Airway secretion clearance by mechanical exsufflation for post-poliomyelitis ventilator-assisted individuals. Arch Phys Med Rehabil 1993;74(2):170-177.

7. Mustfa N, Aiello M, Lyall RA, Nikoletou D, Olivieri D, Leigh PN, et al. Cough augmentation in amyotrophic lateral sclerosis. Neurology 2003;61(9):1285-1287.

8. Senent C, Golmard JL, Salachas F, Chiner E, Morelot-Panzini C, Meninger V, et al. A comparison of assisted cough techniques in stable patients with severe respiratory insufficiency due to amyotrophic lateral sclerosis. Amyotroph Lateral Scler 2011;12(1):26-32.

9. Moran FC, Spittle A, Delany C, Robertson CF, Massie J. Effect of home mechanical in-exsufflation on hospitalisation and lifestyle in neuromuscular disease: a pilot study. J Paediatr Child Health 2013; 49(3):233-237.

10. Bach JR, Wang T. Noninvasive long-term ventilatory support for individuals with spinal muscular atrophy and functional bulbar musculature. Arch Phys Med Rehabil 1995;76(3):213-217.

11. Tzeng AC, Bach JR. Prevention of pulmonary morbidity for patients with neuromuscular disease. Chest 2000;118(5):1390-1396.

12. World Health Organization. International Classification of Functioning, Disability and Health-children \& youth version. Geneva: WHO Press; 2007

13. Arras JD, Dubler NN. Bringing the hospital home. Ethical and social implications of high-tech home care. Hastings Cent Rep 1994;24(5): S19-S28.

14. Shields L, Pratt J, Hunter J. Family centred care: a review of qualitative studies. J Clin Nurs 2006;15(10):1317-1323.

15. Creswell JW. Qualitative inquiry and research design-choosing among five approaches. Los Angeles: Sage Publications; 2007.

16. Liamputtong P. Qualitative research methods. New York: Oxford University Press; 2009.

17. Carel H. Phenomenology and its application in medicine. Theor Med Bioeth 2011;32(1):33-46

18. Bowling A. Research methods in health: investigating health and health services. Berkshire, UK: Open University Press; 2009.

19. Britten N. Qualitative research: qualitative interviews in medical research. BMJ 1995;311(6999):251-253.
20. Hesse-Biber S, Leavy P. The practice of qualitative research. Los Angeles: Sage Publications; 2011.

21. Burnard P, Gill P, Stewart K, Treasure E, Chadwick B. Analysing and presenting qualitative data. Br Dent J 2008;204(8):429-432.

22. Mah JK, Thannhauser JE, McNeil DA, Dewey D. Being the lifeline: the parent experience of caring for a child with neuromuscular disease on home mechanical ventilation. Neuromusc Disord 2008; 18(12):983-988.

23. Lindahl B, Lindblad BM. Family members' experiences of everyday life when a child is dependent on a ventilator: a metasynthesis study. J Fam Nurs 2011;17(2):241-269.

24. Kirk S. Negotiating lay and professional roles in the care of children with complex health care needs. J Adv Nurs 2001;34(5):593-602.

25. Kirk S, Glendinning C. Supporting 'expert' parents-professional support and families caring for a child with complex health care needs in the community. Int J Nurs Stud 2002;39(6):625-635.

26. Kirk S. How children and young people construct and negotiate living with medical technology. Soc Sci Med 2010;71(10):17961803.

27. Earle RJ, Rennick JE, Carnevale FA, Davis GM. 'It's okay, it helps me to breathe': the experience of home ventilation from a child's perspective. J Child Health Care 2006;10(4):270-282.

28. Briscoe WP, Woodgate RL. Sustaining self: the lived experience of transition to long-term ventilation. Qual Health Res 2010;20(1): 57-67.

29. Miller JR, Colbert AP, Schock NC. Ventilator use in progressive neuromuscular disease-impact on patients and their families. Dev M Child Neurol 1988;30(2):200-207.

30. Hauenstein EJ. The experience of distress in parents of chronically ill children-potential or likely outcome? J Clin Child Psychol 1990; 19(4):356-364

31. Jerrett MD. Parents experience of coming to know the care of a chronically ill child. J Adv Nurs 1994;19(6):1050-1056.

32. Carnevale FA, Alexander E, Davis M, Rennick J, Troini R. Daily living with distress and enrichment: the moral experience of families with ventilator-assisted children at home. Pediatrics 2006;117(1): e48-e60.

33. Anderson JM, Elfert H. Managing chronic illness in the family: women as caretakers. J Adv Nurs 1989;14(9):735-743.

34. Coffey JS. Parenting a child with chronic illness: a metasynthesis. Pediatr Nurs 2006;32(1):51-59.

This article is approved for Continuing Respiratory Care Education credit. For information and to obtain your CRCE

(free to AARC members) visit www.rcjournal.com

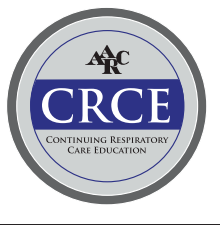

